\title{
HUMANISMI, NIHILISMI JA ELÄIN
}

\section{INKERI KOSKINEN}

Totesin runsas vuosi sitten arviossa, jonka kirjoitin Sari Kivistön ja Sami Pihlströmin kirjasta Sivistyksen puolustus, että olisi hauskaa lukea sellainen perinteisen valistus- ja sivistyshumanismin puolustus, joka vastaisi antihumanistiseen ja posthumanistiseen kritiikkiin. Siksi ilahduin saadessani luettavakseni artikkelin, jossa Pihlström käy taistoon humanismin puolesta.

Pihlström perustaa humanisminsa transsendentaaliargumentille: Ihminen eroaa laadullisesti muista elävistä ja on vääjäämättä oman maailmansa keskushahmo, koska arvoja ja merkityksiä on vain ihmiselle, eikä meillä voi olla kuin ihmisen näkökulma maailmaan. Vain ihminen kykenee kyseenalaistamaan luomansa normatiiviset järjestelmät ja pohtimaan velvollisuuksiaan:"vain ihmiselle on ylipäätään olemassa maailma, joka on säilyttämisen arvoinen ja jonka pelastaminen voi asettua moraaliseksi velvoitteeksi”. Luonnon arvokkuudesta puhuminen edellyttää ihmisen, koska arvokkuudesta puhuminen edellyttää ihmisen. Humanismi ei siis ole valittavissamme; se on väistämätön. Tätä transsendentaalista humanismia Pihlström pyrkii puolustamaan useita kritiikkejä vastaan ${ }^{1}$.

Humanismin kritiikin kritiikki rakentuu artikkelissa edellä kuvatulle transsendentaaliargumentille: kritiikki ei ole virheellistä vaan performatiivisesti ristiriitaista ja siksi mieletöntä. Humanismin kritiikki onnistuu vain ihmiseltä, joten antihumanistinen ja posthumanistinen kritiikki edellyttää transsendentaalisen humanismin.
Minusta näyttää kuitenkin siltä, ettei Pihlströmin transsendentaaliargumentti kanna kaikkea, mitä hän koettaa ripustaa sen varaan. Hän aivan ilmeisesti tahtoo puolustaa sisällökkäämpää humanismia kuin mitä transsendentaaliargumentista seuraa.

Oletettakoon, että humanismin perustava transsendentaaliargumentti yllä kuvatussa ohuessa muodossa pätee. Onko argumentin varassa mahdollista puhua eläimistä kuten Pihlström puhuu? Entä antaako argumentti todella eväät nihilistisen toivottomuuden torjumiseen? Nähdäkseni ei.

Pihlströmin huomiot eläimistä huojuvat hieman. Transsendentaalinen humanismi houkuttelee jyrkkään erontekoon ihmisen ja eläimen välillä: toisin kuin ihmisellä, eläimellä ei ole merkityksiä, ongelmia, arvoja, hyvää eikä pahaa. Pihlström kuitenkin tahtoo yhdistää humanismin naturalismiin välttääkseen essentialistisen ajattelun, joten hän liennyttää eroa: ihmisen ja eläimen erot voivat olla pelkkiä aste-eroja. Mutta liennytyksestä seuraa kysymyksiä, joita Pihlström ei käsittele - ja jotka posthumanistinen ajattelu nostaa esiin. Jos erot ovat aste-eroja, onko ihmisen joskus mahdollista kohdata eläinyksilö samaan tapaan hyvään kykenevänä kuin meidän on mahdollista kohdata toinen ihminen, tai vaikkapa ihmislapsi? Jospa siis emme ihastelisi delfiinien taitoja, vaan kiinnittäisimme sen sijaan huomion tilanteisiin, joissa delfiini on ilmeisen altruistisesti pelastanut ihmisen hengen. Tai kohtaamisiin, joissa ihmisapinat ovat kaikesta päättäen kyenneet tuntemaan jotain, joka kovasti muistuttaa syyllisyyttä tai häpeää. 
Tällaiset tilanteet eivät riitä tekemään eläimistä olentoja, joilla olisi velvollisuuksia. Mutta voimmeko todella huoletta esimerkiksi sanoa, ettei elinympäristön tuhoutuminen koskaan ole eläinyksilölle ongelma?

Humanististen hierarkioiden kyseenalaistaminen on osa sekä antihumanistista että posthumanistista kritiikkiä: valistushumanistiseen ihmiskuvaan sisältyvä käsitys ihanneihmisestä johtaa hierarkiaan, jonka huipulla on ihannetta muistuttava mies ja pohjalla eliökunnan vähäisimmät. Kriitikot kiinnittävät huomionsa siihen, kuinka riippuvainen ihanneihminen on ympäristöstään ja alemmistaan, ja penäävät perusteluita tämän asemalle muiden yläpuolella (ks. esim. Critchley 1999; Barad 2003; Braidotti 2013). Pihlström puolestaan toteaa, että transsendentaalisessa humanismissa hierarkia on väistämätön mutta luonteeltaan toisenlainen kuin kriitikot antavat ymmärtää. Ihmisen asema hierarkian huipulla johtuu siitä, että ihminen yksin kantaa vastuuta. Ihmisen ja eläimen tasavertainen suhde on siksi mahdoton.

Katkelmaa, jossa puhutaan väistämättömän vastuun meille sälyttämästä hierarkiasta, edeltää kuitenkin oiva esimerkki sellaisesta hierarkkisuudesta, jota posthumanistit pyrkivät purkamaan. Pihlström näet ilmoittaa, että ihmisoikeuksien puolustaminen on eläinten hyvinvointia vahvempi perustelu veganismille. Vastuun kantamisen luomasta vääjäämättömästä hierarkiasta siirrytään siis hierarkiaan, jossa ihmisen kokemat välilliset haitat painavat enemmän kuin tehokasvatetun ja -teurastetun eläimen tuska. Pihlströmin transsendentaaliargumentista ei voi johtaa tällaista hierarkiaa, ja juuri tällaisten hierarkioiden ylläpitoon humanismin kriitikot puuttuvat.

Transsendentaaliseen humanismiin sisältyy käsitys siitä, mitä on olla ihminen. Käsitys ei ole kovin sisältörikas, mutta ihmiskuva se on kuitenkin: ihminen on vapaa muuttamaan normejaan ja ihmisellä on arvoja ja merkityksiä. Käyttääkseni G. H. von Wrightin (esim. 1981) erottelua, humanismi kuin humanismi voidaan jakaa kahteen osaan: humanistiseen ihmiskuvaan ja humanismiin elämänasenteena. Jälkimmäinen merkitsee humanistisen ihmiskuvan mukaisen ihmisyyden puolustamista, ihmisen parhaan tavoittelua. Humanistinen elämänasenne tarvitsee siis tuekseen humanistisen ihmiskuvan. Toiseen suuntaan riippuvuussuhdetta ei kuitenkaan ole: humanistinen ihmiskuva ei edellytä humanistista elämänasennetta. Eikä ole uskottavaa, että humanistinen elämänasenne olisi mitenkään välttämätön seuraus myöskään Pihlströmin transsendentaaliargumentista.

Osoittaakseni, kuinka ohuelta transsendentaalinen humanismi minusta vaikuttaa, esitän eräänlaisen ajatuskokeen. Oletetaan pessimismiin taipuvainen transsendentaalinen humanisti. Hän myöntää, että arvoja ja merkityksiä missään meille tutussa mielessä on vain ihmisille. Ja hän myöntää, että tämän seurauksena jokaisella ihmisellä on sellainen arvo, jota millään muulla ei ole. Ihmisyksilön tuhoutuminen kun tarkoittaa potentiaalisesti rajattoman merkityksellisyyden katoamista. Humanistimme ihmiskuva on kuitenkin synkkä: hän ei pidä mahdollisena, että pystyisimme ratkaisemaan aiheuttamamme ympäristökatastrofit. Päin vastoin, hän uskoo ihmisen pahentavan tilannetta, tuottavan kärsimystä ja saattavan muita lajeja sukupuuttoon niin kauan kuin ihmisiä on. Lisäksi hän Pihlströmin sallimalla tavalla antaa ei-inhimilliselle luonnolle suuresti arvoa täysin riippumatta luonnon välinearvosta. Ei ole selvää, että hänen puntarissaan ihmislajin säilyminen pidempään olisi toivottavampi asia kuin monen eläinlajin säästyminen tuholta. Hän voi ristiriidatta toivoa, että ihmislaji nopeasti katoaisi maailmasta, vaikka se veisi mukanaan arvot ja merkitykset siinä mielessä kuin me ne ymmärrämme.

Painotan nyt vielä erikseen, etten itse kannata tällaista humanistista nihilismiä enkä tiedä ketään muutakaan, joka sitä kannattaisi. Tarkoitukseni oli vain havainnollistaa, millaisia kantoja transsendentaalisen humanismin piiriin mahtuu, ja korostaa Pihlströmin 
transsendentaaliargumentin välttämättömien seurausten ohuutta verrattuna siihen kokonaiskantaan, jota hän puolustaa.

Olen Pihlströmin kanssa samaa mieltä siitä, etteivät antihumanistiset ja posthumanistiset humanismin kriitikot onnistu irrottautumaan humanismista. Pidän siksi aiheellisena

\section{VIITTEET}

1 Sanottakoon, etten ole vakuuttunut aivan kaikkien Pihlströmin esittämien vastaväitteiden tarpeellisuudesta. En ole koskaan törmännyt sellaiseen termin "antroposeeni" käyttöön, jossa redusoitaisiin ihmisen merkitys maailmassa "(pseudo)geologiseen kauteen" tai ihmisen erityisyys "kausaaliseen voimaan". Holoseenin jälkeiselle geologiselle epookille on ehdotettu nimeä "antroposeeni". Kun puhutaan geologisista epookeista, huomio tietysti kiinnittyy asioihin, jotka voidaan havaita geologian keinoin. Tämä ei kuitenkaan edellytä tai mitenkään tarkoita ihmisen merkityksen tai erityisyyden redusoimista mihinkään. lukea heidän esittämäänsä kritiikkiä humanismin sisäisenä itsekritiikkinä; perinteisen valistushumanismin kritiikkinä. Näin tulkittuina kritiikki haastaa muutamia Pihlströmin puolustamia kantoja tavalla, johon en ole toistaiseksi nähnyt tyydyttävää vastausta.

\section{KIRJALLISUUS}

Karen Barad, Posthumanist Performativity: Toward an Understanding of How Matter Comes to Matter. Signs: Journal of Women in Culture and Society. Vol. 28, No. 3, 2003.

Rosi Braidotti, The Posthuman. Polity, Cambridge, 2013.

Simon Critchley, Post-Deconstructive Subjectivity. Teoksessa Simon Critchley, Ethics - Politics - Subjectivity. Essays on Derrida, Levinas and Contemporary French Thought. Verso, Lontoo, 1999.

Georg Henrik von Wright. Teoksessa Humanismi elämänasenteena (Humanismen som livshållning och andra essayer, 1978). Suom. Kai Kaila. Otava, Helsinki, 1981. 